\title{
Overall Optimization of the Theory and Practice in Computer Control System Curriculum
}

\author{
Haishuang Guan ${ }^{1, a}$ and JianMin Zhang ${ }^{1, b^{*}}$ \\ ${ }^{1}$ College of Electrical and Information Engineering, Beihua University, Jilin, 132013, China \\ aguanhaishuang@163.com, ${ }^{*} 1787043057 @ q q . c o m$ \\ *The Corresponding author
}

Keywords: Computer system technology; Project teaching; Inquiry learning; Practice teaching

\begin{abstract}
In this paper, according to the problems of the course in theory and practice, it gives some concrete measures and results on the course reform of computer control system, respectively from the teaching content, teaching methods, practical teaching, experimental teaching and assessment methods, etc. To further deepen teaching reform has carried on the beneficial attempt.
\end{abstract}

\section{Introduction}

With the transformation of the higher education from traditional exam-oriented education to the modern comprehensive quality education, the traditional teaching mode is moving towards the development goals of learning theory knowledge, improving the comprehensive quality, enhancing practice ability and cultivating innovation spirit and innovation ability.

Computer control system curriculum is an important basic professional course of automation majors of automation, electrical engineering and its automation, measurement and control technology, instrument, etc [1-3]. The curriculum has a strong practicality and is related to the professional courses closely. And it is the outcome of the organic combination and comprehensive development of computer technology (including software technology, interface technology, communication technology, network technology and display technology), automatic control technology, microelectronic technology, automatic detection and sensor technology [4-5]. So students should understand and grasp how to choose and organize the software, hardware, peripheral equipment and the interface channel of the industrial personal computer and also should understand and grasp how to control and manage the fundamental principle and method in the productive process. The controlled object, computer, sensor, channel and interface, actuator, system software and kinds of application softwares should be organized into an organic whole and form a complete computer system to achieve a scheduled purpose.

With the rapid development of science and technology, computer control technology has been widely applied to the industrial and agricultural production, communication and transportation, national defense construction and other fields and also plays a more and more important role. Establishing the concept of the computer control system and grasping the basic theory and basic design method of the computer control system have become the urgent affairs for engineering students to adapt to the new situation and new technique development.

\section{Problems in the Curriculum Teaching}

More Theory Class Hours but Less Practice Class Hours, and the Poor Students Practical Ability. At the present, this curriculum is lectured as a theory course in many universities and it adopts a teaching mode which relys mainly on classroom teaching while taking the experiment as the subsidiary. This curriculum is a professional and comprehensive course which covers lots of contents, so in order to lecture the course content comprehensively and systematically, the experiment hours should be limited necessarily[6-7]. But if we reduce the theory class hours blindly, the systematicness and the integrality of the curriculum content will also be affected. Therefore, the students always feel 
that this curriculum is a theory course and they also feel confused when they are in the face of the practical system.

The Content of the Experiment Teaching is Monotonous. Currently, the experiment which is offered by lots of colleges for the computer control system is just a simple demonstrated and verified experiment, such as the A/D conversion experiment, the stepping motor control experiment, etc. However, the comprehensive development experiment is set less. Students often grasp the simple demonstrated experiment very well, but when they face the systematic design and development, they don't how to do and how to convert the theory knowledge into the practical operation.

The Examination Method is Unitary and Cannot Really Reflect the Real Level of the Students. This curriculum generally adopts the closed-book exam method which greatly relies on the textbook, therefore many students learn it by rote in order to get high scores[8]. As for the students who like thinking independently and are interested in solving practical problems but are not good at learning by rote, their scores may be not very high, therefore, there are great drawbacks to appraise students by a piece of test paper and also this way cannot appraise the practical ability of the students comprehensively.

\section{Curriculum Characteristics}

The strong applicability. The computer control technology is more and more applied in a widely area and plays an indispensable role in modern industrialization.

The strong renewal nature. With the continuous development of the computer technique and automatic control theory, the teaching content is updated continuously.

The strong comprehensiveness. This curriculum involves electronic technique, automatic control theory, process control, microcomputer principle and application and other aspects of knowledge and it also colligates many basic theories and previous curriculums.

The strong practicality. This curriculum is a typical course which needs to link the theory with practice. It requires students to achieve the trinity of the theory analysis, system design and experiment and also it can cultivate the consciousness and ability of the integration of the science, technology and engineering of the students.

The computer control system has both theory and practice, so we can't neglect the vital function of the classroom teaching and experimental teaching, and it is also necessary to research, explore and practice the two teaching methods.

\section{The Reform of the Theoretical Teaching}

Adjusting the Teaching Content to Form the New Mode of System Integration. The establishment of the system concept is one of the ultimate training targets for the students who major in industrial automation to achieve. We should adjust the teaching content and highlight the system concept to form the teaching content which takes the classical control system and modern control system as the foundation, takes the bus industrial computer as the control tool, takes the microcomputer hardware and software technology as means and takes the engineering realization of the system as the aim[9-10]. Thus, the theory, technology and practical application can be combined, the traditional mode from chip to system can be changed fundamentally and the new mode of system integration can be adopted.

Based on the engineering practice, the students should detailedly study the design method of the hardware and software of the serial communication control system, distributed control system and data acquisition and control system through training projects. These projects highlight the software design, aiming at achieving the functions.

The teaching content of each project includes project context, learning target, training tasks, training operation, consolidation and improvement, knowledge links, learning and thinking questions, etc. 
Improving Teaching Method and Adopting the New Teaching Mode and Measures. This curriculum is a professional course with a strong practice[11-12]. The laws of teaching are: in the content, we should pay equal attention to the physical concept, mathematical concept and engineering concept; in the method, we should adopt the way of the combination of theoretical teaching, experimental design and production, curriculum design and large scale comprehensive experiment and introduce CAI and multimedia teaching gradually.

Therefore, in the process of teaching, we should reform the traditional teaching form, teaching means and teaching method, take the ability improvement as the center and adopt new teaching modes and measures to achieve the transformation from knowledge cultivation to ability cultivation.

The Teaching Method of the Interaction Between the Teachers and Students. The classroom atmosphere plays an important role in teaching quality, therefore the teaching method of the interaction between teachers and students is adopted. In this method, firstly the teacher raises a question to guide the students to think and then conducting a discussion which can allow full play to the students' subjective initiative, stimulate students' interest in learning and brisk the classroom atmosphere. This method is helpful for students to understand, deepen and expand the teaching content.

Encouraging the Students to Carry on an Inquiry-based Learning and Investigative Study. In the process of teaching, in addition to the content of teaching part, some contents which are closely related to the practical engineering should be reserved for the students to carry on the inquiry-based learning. Or the teachers should give students a task which is in the form of large assignment to prompt students to search the information actively and improve the ability of solving problems independently. Meanwhile, the network resources should be used fully and the database should be established to facilitate the students to consult.

Emphasis on Practical Teaching Method. In the course of teaching, the teachers should pay more attention to the emphasis on practical teaching method and the theory should be linked with the practice properly. And teachers should teach some difficult problems and some ideas of solving problems, which combine with the theory knowledge of the book in the course of teaching. Thus, students can be attracted and the ability of solving problems of students can also be enhanced.

Multimedia Teaching. The system model which cannot be established now can be constructed by using computer simulation method and also based on the modern computer technology, the simulation teaching can be combined with the theory explanation throughout the whole teaching process to improve the imagination and creativity of students.

There are many figures in the teaching of this curriculum, especially typical links of the system or the electrical circuit of the components, the waveform in the dynamic process, the circuit of the basic unit and so on. If without the help of graphic analysis, the teachers can't express the knowledge clearly, but if they are drawing while teaching, they will waste lots of time. Therefore, students can understand the difficult knowledge deeply by using the courseware which is designed by teachers.

For the teaching content of computer control theory, the multimedia technology is adopted to assist classroom teaching, for example, the MATLAB is adopted to simulate the control system and the dynamic process of the figure can increase the perceptual knowledge of students and the change of the font, color, background color, shading and border of the Power point software is used to emphasize the key content.

Multimedia teaching means cannot only increase the information content of the teaching, but also can advise and review key and difficult points of the illustrations and curriculums repeatedly.

Network Resource. The network resources should be used fully, and aiming at the classroom contents, the students should be encouraged to consult the relevant document literatures as the usual appraisal performance. 


\section{The Cultivation of the Practical Teaching Reform and Innovation Ability}

Experimental Teaching Reform. Aiming at the key knowledge of the curriculum, the compulsory experimental projects should be set. According to the experimental situation of students from different majors, the summary is made and the contents of the comprehensive and innovative experiment are reset. Students are asked to draw inferences in the process of verification experiment and deepen the understanding of the theory knowledge to achieve the combination of the knowledge and ability.

The aim of the experimental teaching is to cultivate the ability of the practical operation and the ability of solving practical problems of students. The experimental teaching and the theory teaching always reinforce each other. In order to cooperate the classroom teaching better, improve the quality of the experiment and achieve the demand of the experiment, the reforms of the experimental teaching are as follows:

Students are asked to write a preview report before the experiment. After the completion of the experiment, the teacher should check and accept the experiment datum and figures of each student one by one and ask students to explain the ideas of the system design, compiling method, etc. Students should answer the spot questions which are asked by teachers and complete the report writing of the experiment independently. And based on these, the grasp degree of the knowledge and the ability of the operation of students can be inspected comprehensively.

Reducing the verification experiment but increasing the designing, innovative and comprehensive experiments, such as the single-capacity tank liquid level constant value control system. Students can observe the application prospect of the technology which is involved in this curriculum in the process of experiment and feel the fun of solving specific engineering technology problems by using the knowledge of this curriculum, thus their learning quality can be improved.

In the way of the experiment completion, the open experiment should be adopted to make students complete the experiment in a free and flexible way and to stimulate the enthusiasm of students.

Curriculum Design Reform. Curriculum design is an important part of the comprehensive training in the teaching plan. It can make students get the systematic training to use the learned knowledge comprehensively and solve the practical questions of their own majors[13]. In order to make a good curriculum design and cultivate the practical ability of students, three requirements, two strictnesses, and one relaxed environment should be done in the process of practical operation.

Three Requirements. There are instructional time and content arrangement plans. Before the class, teachers should give instructional time and content arrangement plans to students and emphasize the key points to make students know them in the process of design, thus the design efficiency can be improved.

There is a specific aim to cultivate students' ability. The ability which needs to be cultivated are as follows: the ability of combining theory with practice, the ability of analyzing and solving problems, the ability of programming, the ability of consulting information and device using handbook, the ability of design description and literature review, the ability of market research and the ability of scientific and technological innovation.

There are feasible operation regulations which can promise to put the ability cultivation into effect. In the actual implementation process, the whole process of curriculum design is divided into two implementation stages. And the time of the computer control system curriculum design is two weeks. In the first week, students are asked to make the design scheme (the hardware circuit diagram and the program chart), survey the market price of the parts which will be used in the design, etc. The investigation ability of students can be cultivated. In the second week, students should be asked to connect the hardware, debug the software and then the results will be gained. The instructor will check whether the design achieves the requirement and finally the students will write the report.

Two Strictnesses. Students should be asked to design the scheme and debug by themselves strictly. About five students have one topic but each one is asked to design and debug programming by using one machine. 
Strict acceptance inspection. At the end of debugging, each student is asked to program the routine which is designed by them in the position of the computer and give it to their instructor to check and accept.

One Relaxed Environment, the relaxed learning environment. Students should be encouraged to express their own opinions in the aspects of the scheme design, source routine programming and chip selection to mobilize the subjective initiative of them.

\section{Multiple Evaluation Methods and the Comprehensive Ability of Students are Inspected}

In the reform aspects of appraisal content and method, the comprehensive quality and innovation ability of the students should be appraised scientifically and comprehensively. We should pay more attention to the appraisal of the learning ability of the investigative study, explorative learning and collaborative learning of the students and explore the diversified appraisal methods actively to make the appraisal more comprehensive.

The evaluation method is a means to promote learning not a aim. The scientific evaluation method not only can stimulate the learning enthusiasm of the students but also can stimulate the teachers' enthusiasm. From the point of evaluation method, there are many forms which are attendance, classroom quiz, big homework, experiment, open book examination, closed book examination, course paper, etc. The evaluation method before this curriculum is: the final closed book exam $80 \%+$ experiment $10 \%+$ usual score $10 \%$. The final exam score is the main score, therefore the learning enthusiasm of students in usual is not very high, and many students just study in the final period.

Therefore, the following evaluation method is put forward: the final closed book exam $40 \%+$ big homework $20 \%+$ usual score $20 \%+$ experiment $20 \%$. The content and form of the assessment become more flexible and various. The study and exploration of the students can be stimulated in usual. And the assessment results will become more convincing because of the emphasis on practical ability.

Meanwhile, the tutorship means of the discussion online and net answer can be adopted in usual to enhance the interaction between teachers and students to improve the learning enthusiasm of students.

\section{Summary}

Practice has proven that in the reform process of the theory and the practical teaching of computer control system curriculum, through the endeavor of the above several aspects, the professional interest of students is cultivated, the innovation consciousness of students is enhanced and the operation ability and the practical application ability of students are improved. And a good teaching effect has been acquired in the process of teaching and practice.

However, there are also some problems and shortcomings. We hope that in the future teaching research and teaching practice, a better method will be explored to achieve the cultivation goal to improve the ability of analyzing and solving problems of students and enhance the innovation ability of students.

\section{References}

[1] J.Q. Li, Computer Control Technology Project Tutorial, E-Publishing Mechanical Industry Press, BeiJing, 2009, pp. 1-15.

[2] H.Xing, T.M. Zhang, Discussion and Practice on Computer Control Technology Course Reformation, J.Reseach and Exploration in Laboratory, 12 (2007) 370-372.

[3] Y. Ju, An Exploration into the Teaching Method Reform of Computer Control Technique, J. Journal of Nanjing Institute of Technology(Social Science Edition). 1 (2007) 45-47.

[4] X.X. Zhou, R.J.Song and D. Niu, The Research of the innovation in Teaching the Course of Computer Control Technology, J.Journal of Northeast Dianli University Natural Science Edition,3(2008) 29-31. 
[5] X.J. Zhu, Study on Teaching Method of Computer Control System Course, J. Journal of Shengyang Institute of Engineering(Social Science Edition), 3 (2010) 431-433.

[6] S.Q. Xu, Teaching reform and practice of computer control technology course for excellence plan, J. Network and information engineering, 17 (2015) 93-94.

[7] Y. Zhao, L.Kang and M. Jiang, Exploration of curriculum reform of computer control system, J. China electric education, 30 (2014) 59-61.

[8] X.L. Liu, Z. Zhang, Y. Zhao and M. Jiang, Teaching reform and exploration of computer control system curriculum based on case teaching, J. Electronics world, 10 (2016) 133-134.

[9] L.J. Xiang, X.M. Hong, L.X. Zheng and Y.Y. Xu, Exploration and research on computer control system course reformation based on ability cultivation, J. China modern education equipment, 17 (2014) 65-68.

[10] Y. Chen, L.S. Liu, F. Wang and H.J. Xiao, On the Practice Teaching Reform of Computer Control System Based on Single Chip Microcomputer, China modern education equipment, 251 (2016) 36-39.

[11] Y. Zhao, L.Kang and M. Jiang, Teaching reform and exploration of computer control system curriculum based on case teaching, J. Electronics world, 10 (2016) 133-134.

[12] Information on http://www.icourses.cn/coursestatic/course_4391.html

[13] Information on http://www.icourses.cn/coursestatic/course_3979.html 